OPEN

SUBJECT AREAS:

HETEROGENEOUS

CATALYSIS

SURFACE ASSEMBLY

Received

17 October 2014

Accepted

6 November 2014

Published

28 November 2014

Correspondence and requests for materials should be addressed to

C.K.N. (narulack@ ornl.gov)

\section{Remarkable NO oxidation on single supported platinum atoms}

\author{
Chaitanya K. Narula' ', Lawrence F. Allard', G. M. Stocks' \& Melanie Moses-DeBusk²
} 1Materials Science \& Technology Division, Oak Ridge National Laboratory, Oak Ridge, TN 37831 -6133, ${ }^{2}$ Energy \& Transportation
Science Division, Oak Ridge National Laboratory, Oak Ridge, TN 37831.

Our first-principles density functional theoretical modeling suggests that NO oxidation is feasible on fully oxidized single $\theta-\mathrm{Al}_{2} \mathrm{O}_{3}$ supported platinum atoms via a modified Langmuir-Hinshelwood pathway. This is in contrast to the known decrease in NO oxidation activity of supported platinum with decreasing Pt particle size believed to be due to increased platinum oxidation. In order to validate our theoretical study, we evaluated single $\theta-\mathrm{Al}_{2} \mathrm{O}_{3}$ supported platinum atoms and found them to exhibit remarkable $\mathrm{NO}$ oxidation activity. A comparison of turnover frequencies (TOF) of single supported Pt atoms with those of platinum particles for NO oxidation shows that single supported $\mathrm{Pt}$ atoms are as active as fully formed platinum particles. Thus, the overall picture of NO oxidation on supported Pt is that NO oxidation activity decreases with decreasing $\mathrm{Pt}$ particle size but accelerates when $\mathrm{Pt}$ is present only as single atoms.

xides of nitrogen $\left(\mathrm{NO}_{\mathrm{X}}\right)$ are highly reactive gases that are emitted from cars, trucks and buses, power plants, and off-road equipment. These oxides contribute to ground level ozone and are known to have adverse effects on the human respiratory system. The abatement of nitrogen oxides generally involves an oxidation step to convert them all to $\mathrm{NO}_{2}$ which can then be reduced to nitrogen with a reductant. Typically, a supported platinum catalyst is employed for the oxidation step ${ }^{1-3}$, which is equilibrium limited over the temperature range of interest ${ }^{4,5}$. The weak and kinetically labile $\mathrm{ON}-\mathrm{O}$ bond makes $\mathrm{NO}_{2}$ even more effective at dosing a catalyst surface than $\mathrm{O}_{2}$. This $\mathrm{NO}_{2}$ dosing has been proposed to control platinum surface oxygen during $\mathrm{NO}$ oxidation $^{6-12}$. The degree of surface oxygen coverage achieved during dosing and the oxygen binding energy depend on the concentrations of the reactants and products during the NO oxidation reaction. The dependence of NO oxidation on platinum particle size is well-known, with $\mathrm{NO}$ oxidation diminishing as the platinum particle sizes decrease ${ }^{11}$. Earlier studies failed to show if the cluster size effect is due to inactive Pt oxides or the presence of stronger surface Pt-O bonds in small clusters ${ }^{11}$. A recent detailed kinetic and isotopic study showed that large Pt clusters, which bind oxygen weakly as compared with smaller clusters, have higher vacancy concentrations and facile oxygen desorption ${ }^{13}$. First principles theoretical modeling of an $\mathrm{NO}$ interaction with a $\mathrm{PtO}_{2}(110)$ surface shows that the surface has a weak ability to bind $\mathrm{NO}$ and $\mathrm{O}$ resulting in a high barrier $(1.78 \mathrm{eV})$ for $\mathrm{O}_{2}$ dissociation ${ }^{14}$.

Since single supported atoms are the smallest possible clusters, it can be postulated that NO oxidation on such catalysts will be quite ineffective, especially since they are fully oxidized. However, supported single atom catalysts have generally been found to be more reactive than metal clusters or particles ${ }^{15-22}$. For example, the atomic dispersion of noble metal atoms was found to be the active species in the water-gas shift reaction ${ }^{15}$. Monodisperse palladium atoms on alumina, even at $0.03 \%$ loading, are highly active towards the selective oxidation of allylic alcohols ${ }^{16}$. Monodisperse single Pt atoms on iron oxide were shown to be highly active for CO oxidation and preferential CO oxidation in the presence of hydrogen ${ }^{17}$. Iridium single atoms on iron oxide exhibit high specific activity for the water gas shift reaction ${ }^{18}$. Monodisperese single Pt atoms on inert $\theta$-alumina substrate are also highly active towards CO oxidation which occurs via a modified Langmuir-Hinshelwood (L-H) pathway ${ }^{19}$. Low temperature $\mathrm{CO}$ oxidation has been observed on single supported Pd atoms ${ }^{20}$. High catalytic activity of single supported silver atoms has been demonstrated by their ability to oxidize formaldehyde at low temperatures ${ }^{21}$. Finally, single atoms of rhodium are highly active toward methane reforming ${ }^{22}$. To our knowledge, there is no report describing NO oxidation on single supported atoms. It is important to point out that the study of NO oxidation on single atoms and rafts is relevant to $\mathrm{NO}_{\mathrm{X}}$ abatement because single atoms and small rafts are present in fresh emission treatment catalysts along with well-defined Pt nanoparticles.

From a bonding perspective, NO bonded in a bent mode (M-N-O angle below $\left.160^{\circ}\right)$ to metals is considered to be $\mathrm{NO}^{+}$which is isoelectronic with $\mathrm{CO}$. As such, we reasoned that $\mathrm{NO}$ oxidation can also occur via the modified $\mathrm{L}-\mathrm{H}$ scheme proposed previously for single $\mathrm{Pt}$ atom catalyzed CO oxidation ${ }^{19}$. However, NO oxidation is 


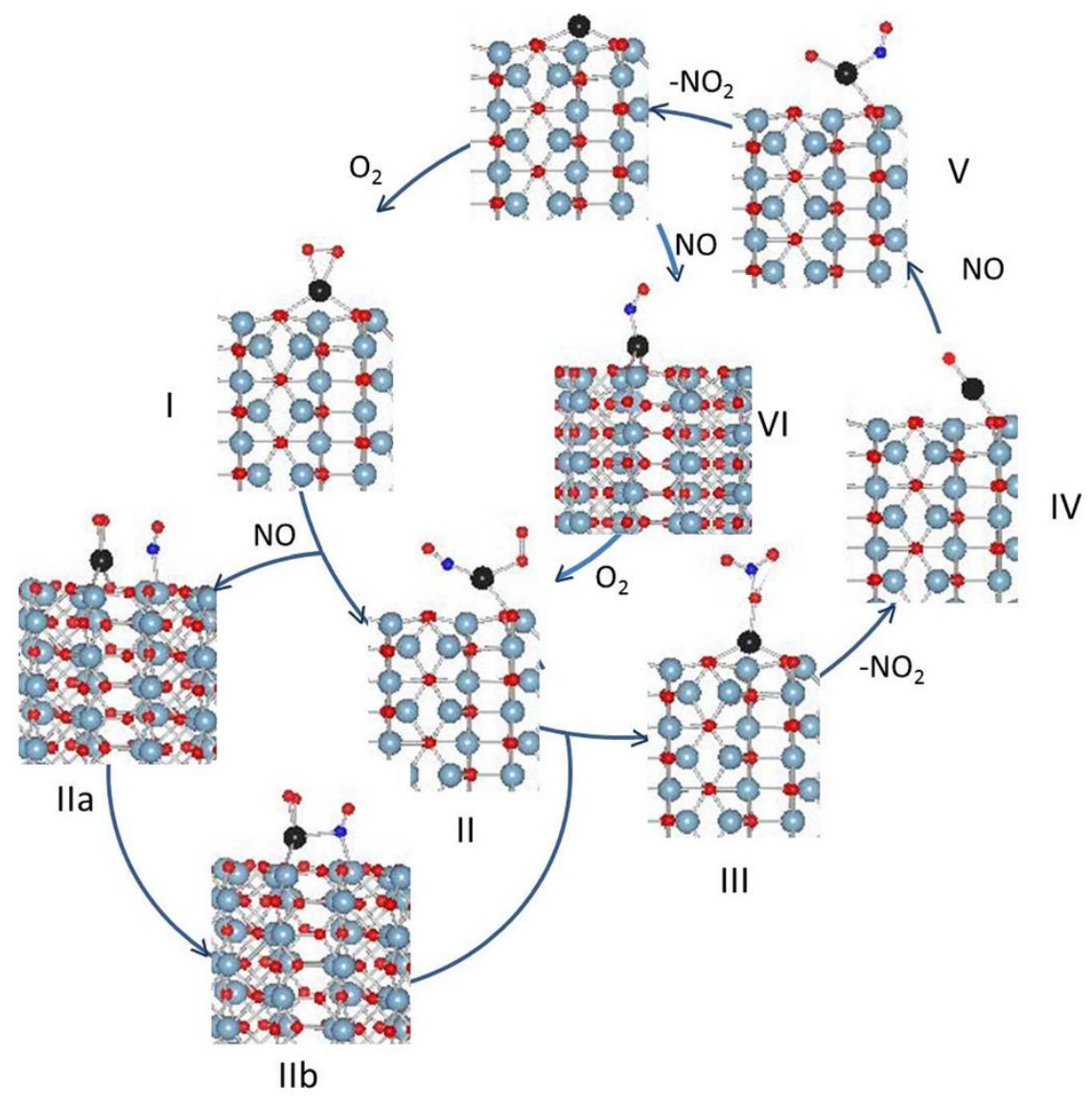

Figure 1 Pathways for NO oxidation on single Pt atoms supported on the (010) surface of $\theta-\mathrm{Al}_{2} \mathrm{O}_{3}$ [oxygen - red, aluminum - light blue, platinum black, and nitrogen - blue].

complicated by the fact that it is less exothermic than $\mathrm{CO}$ as evident from a $\Delta \mathrm{H}$ of reaction of $-0.59 \mathrm{eV}$ (cf. $-2.93 \mathrm{eV}$ for $\mathrm{CO}$ ) and is equilibrium limited over the desired temperature range $e^{4,5,23}$. Thus, conclusions from the $\mathrm{CO}$ oxidation study are not applicable to $\mathrm{NO}$ oxidation $^{24}$. Despite these considerations, our first principles study predicts that NO oxidation on single supported Pt atoms can proceed via a modified L-H mechanism. Our experimental work shows that single supported platinum atoms are indeed active for $\mathrm{NO}$ oxidation. The turnover frequency (TOF) of single supported Pt atoms is comparable to well-formed Pt particles. Thus, the overall picture of NO oxidation on supported Pt is that NO oxidation activity decreases with decreasing Pt particle size but accelerates when $\mathrm{Pt}$ is present only as single atoms or agglomerates of single atoms (e.g. rafts).

\section{Results \& Discussion}

NO Oxidation Pathway on Single Pt Atoms on $\boldsymbol{\theta}-\mathrm{Al}_{2} \mathrm{O}_{3}$. The oxidation of $\mathrm{NO}$ on $\mathrm{Pt}$ (111) surfaces has recently been examined by Schneider et $\mathrm{a}^{25}$. Their results suggest that a high concentration of chemisorbed $\mathrm{O}$ is needed for $\mathrm{NO}$ oxidation on Pt but that the surface oxides are detrimental to reaction kinetics. $\mathrm{O}$ atoms were found to prefer FCC binding sites and arrange themselves to minimize destabilizing interactions with neighboring oxygens. Their results also show that the dissociative equilibrium of $\mathrm{O}_{2}(\mathrm{~g})$ can produce coverage of up to $1 / 2$ monolayer. The $\mathrm{NO}_{2}$ decomposition or NOassisted $\mathrm{O}_{2}$ dissociation can increase coverage up to the $2 / 3$ monolayer normally observable during NO oxidation catalysis. Thus, Schneider et al. provide a useful guide via "Ellingham" free energy diagram of various oxidation reaction energies towards detailed reaction kinetics studies.

Unlike supported Pt particles, the single supported Pt atoms exist only as oxidized species under ambient or oxidizing conditions ${ }^{19}$.
This implies that there is at least a monolayer coverage of oxygen on all single Pt atoms. The reduced form, where no oxygen is adsorbed on Pt atoms, can be stable as a transition state during a catalytic process ${ }^{19,26}$. For NO oxidation, the pathway shown in Figure 1 builds upon the recently published first-principles study of $\mathrm{Pt}$ atoms supported on the (010) surface of $\theta-\mathrm{Al}_{2} \mathrm{O}_{3}{ }^{25}$ and the proposed pathway for $\mathrm{CO}$ oxidation on supported $\mathrm{Pt}$ atoms ${ }^{19}$.

The total energies of optimized species in Figure 1 are summarized in Table S1. The platinum atoms adsorb on the alumina surface in bridging positions between two oxygen atoms and are in a $\mathrm{d}^{10}$ oxidation state ${ }^{26}$. An oxygen molecule can bond to a Pt atom in a side-on chelating mode ${ }^{19}$. Unoccupied $d_{x y}$ orbitals and the lack of magnetization support a $\mathrm{d}^{8}$ structure for $\mathrm{Pt}$ atoms after oxygen bonding. Adsorption of $\mathrm{NO}$ on an oxidized $\mathrm{Pt}$ atom results in intermediate II [Figure 1]. NO bonds to $\mathrm{Pt}$ in a straight mode with a Pt-N-O angle of $163.8^{\circ}$ suggesting a formal $\mathrm{NO}^{-}$mode. Simultaneously, one of the $\mathrm{Pt}-\mathrm{O}$ surface bonds breaks while the other surface $\mathrm{Pt}-\mathrm{O}$ bond slightly lengthens by $0.06 \AA$ to $2.248 \AA$. The side-on configuration of molecular oxygen also changes to terminal with a Pt-O bond of $2.06 \AA$. The magnetic moment is now localized completely on molecular oxygen suggesting a $\mathrm{d}^{8}$ or $\mathrm{d}^{10}$ platinum species [Table S2]. The projected density of states orbital (PDOS) analysis shows partially filled $\mathrm{d}_{\mathrm{xy}}$ and $\mathrm{d}_{\mathrm{x} 2}$ confirming a $\mathrm{d}^{8}$ platinum [Figure $\mathrm{S} 1$ ].

We also explored an alternative pathway that involves NO bonded to aluminum adjacent to single $\mathrm{Pt}$ atoms. The $\mathrm{NO}$ molecule bonds to $\mathrm{Al}$ in a bent mode ( $\mathrm{Al}-\mathrm{N}-\mathrm{O}$ angle of $139.8^{\circ}$ ) and the non-bonding Pt$\mathrm{N}$ distance is $2.52 \AA$. The total energy of configuration IIa is $-1339.1865 \mathrm{eV}$ which is $1.84 \mathrm{eV}$ higher than that of configuration II. In another possible configuration (IIb), which can form from either IIa or I, the NO molecule bonds to $\mathrm{Al}$ in a bent mode (Al$\mathrm{N}-\mathrm{O}$ angle of $132.56^{\circ}$ ) and bonds to Pt with Pt-N bond distance of 
$2.24 \AA$. The total energy of configuration IIb is $-1339.2808 \mathrm{eV}$, which is also $1.75 \mathrm{eV}$ higher than that of configuration II. These results suggest that NO oxidation can proceed on single supported $\mathrm{Pt}$ atoms without involving surface aluminum.

The rearrangement of II to a nitrate species in III is an endothermic step $(1.09 \mathrm{eV})$. The nitrate species bonds to platinum in a mono-dentate mode. Such a mode has been previously observed for trans-Nitrato[2-(di-tert-butylphosphino)phenyl]-di-tert-butylphenylphosphine-platinum(II) with a Pt-O bond distance of $2.17 \AA^{27}$. The calculated bond distance of $\mathrm{Pt}-\mathrm{O}$ for the nitrate bonded to $\mathrm{Pt}$ in III is $2.09 \AA$. The platinum and all oxygen atoms on nitrogen carry a magnetic moment [Table S2], suggesting a $\mathrm{d}^{9}$ oxidation state for Pt. The projected density of state analysis [Figure S2] shows $5 \mathrm{~d}_{\mathrm{xy}}$ is partially filled. The loss of $\mathrm{NO}_{2}$ from III to form IV is also an endothermic process $(1.24 \mathrm{eV})$. As described previously, IV is a high spin Pt species with partially filled $\mathrm{Pt} \mathrm{d}_{\mathrm{xy}}$ and $\mathrm{d}_{\mathrm{yz}}$ orbitals ${ }^{19}$. The Pt-O bond distance with the remaining oxygen in IV contracts to $1.79 \AA$, while the Pt-O bond distances from surface oxygen become $0.2 \AA$ larger suggesting a weaker support interaction than the non-oxidized platinum atom. The reaction of IV with $\mathrm{NO}$ to form $\mathrm{V}$ is an exothermic reaction. The Pt-N-O angle is $134.29^{\circ}$ suggesting a formal $\mathrm{NO}^{+}$bonding mode (bent NO). The formation of the Pt-NO bond accompanies a break-up of one Pt-surface oxygen bond and lengthening of the other Pt-surface oxygen bond, suggesting a weakening of support interactions. Magnetization in intermediate $\mathrm{V}$ is on platinum, adsorbed oxygen, nitrogen and oxygen of adsorbed NO suggesting a $\mathrm{d}^{9}$ platinum species. The PDOS analysis [Figure S3] shows partially filled $\mathrm{d}$ orbitals with vacancies in $\mathrm{d}_{\mathrm{xy}}$ and $\mathrm{d}_{\mathrm{xz}}$. Elimination of $\mathrm{NO}_{2}$ from $\mathrm{V}$ leads to a single supported $\mathrm{Pt}$ atom which restarts the $\mathrm{NO}$ oxidation cycle by oxygen adsorption. The NO adsorption is energetically less favorable than oxygen adsorption. The most favorable mode of $\mathrm{NO}$ adsorption is bent mode ( $\mathrm{Pt}-\mathrm{N}-\mathrm{O}$ angle of $135.9^{\circ}$ ) shown in configuration VI in Figure 1. Other adsorption modes [Figure S4] did not optimize. In bent adsorption mode, the adsorption energy is $-1.66 \mathrm{eV}$ which is $\sim 0.21 \mathrm{eV}$ more than $\mathrm{O}_{2}$ adsorption on single supported $\mathrm{Pt}$ atom in configuration I. Magnetization in intermediate VI is on platinum, nitrogen and oxygen of adsorbed NO suggesting a $\mathrm{d}^{9}$ platinum species. The PDOS analysis [Figure S5] shows partially filled $d$ orbitals with vacancies in $d_{x y}$ and $d_{x z}$.

The energetics of reactions in Figure 1 can be summarized as presented in Table 1. The calculations in the table are based on total energies summarized in Table S1. All proposed reactions are energetically favorable except there is a barrier to nitrate formation and its decomposition. Thus, the first principles modeling results predicts that there is a pathway for NO oxidation on fully oxidized single supported Pt atoms. The experimental studies, described in the following paragraphs, show that single supported $\mathrm{Pt}$ atoms indeed catalyze NO oxidation.

NO Oxidation on $\boldsymbol{\theta}-\mathrm{Al}_{2} \mathrm{O}_{3}$ Supported Single Pt Atoms. The steady state $\mathrm{NO}$ oxidation on $0.18 \% \mathrm{Pt} / \theta-\mathrm{Al}_{2} \mathrm{O}_{3}$ shows $\sim 4 \%$ conversion at $265^{\circ} \mathrm{C}$ that increases only slightly to $\sim 6 \%$ at $315^{\circ} \mathrm{C}$ but reaches $\sim 15 \%$ at $415^{\circ} \mathrm{C}$. This NO oxidation activity is much higher than that observed for blank $\theta-\mathrm{Al}_{2} \mathrm{O}_{3}$ support [Figure S5]. Furthermore,

\begin{tabular}{|c|c|c|}
\hline $\begin{array}{l}* \mathrm{Pt}+\mathrm{O}_{2} \\
* \mathrm{Pt}+\mathrm{NO} \\
* \mathrm{Pt}\left(\mathrm{O}_{2}\right)+\mathrm{NO} \\
* \mathrm{Pt}\left(\mathrm{O}_{2}\right)(\mathrm{NO}) \text { (II) } \\
* \mathrm{Pt}\left(\mathrm{NO}_{3}\right)(\mathrm{III})-\mathrm{NO}_{2} \\
* \mathrm{Pt}\left(\mathrm{O}_{2}\right)(\mathbf{I V})-\mathrm{O} \\
* \mathrm{Pt}(\mathrm{O})(\mathbf{I V})+\mathrm{NO} \\
* \mathrm{Pt}(\mathrm{O})(\mathrm{NO})(\mathbf{V})-\mathrm{NO}_{2}\end{array}$ & $\begin{array}{l}=* \operatorname{Pt}\left(\mathrm{O}_{2}\right)(\mathbf{I}) \\
=* \operatorname{Pt}(\mathrm{NO})(\mathbf{V I}) \\
=* \operatorname{Pt}\left(\mathrm{O}_{2}\right)(\mathrm{NO})(\mathbf{I I}) \\
=* \operatorname{Pt}\left(\mathrm{NO}_{3}\right) \text { (III) } \\
=* \operatorname{Pt}(\mathrm{O})(\mathbf{I V}) \\
=* \operatorname{Pt}(\mathrm{O})(\mathbf{I V}) \\
=* \operatorname{Pt}(\mathrm{O})(\mathrm{NO})(\mathbf{V}) \\
=* \operatorname{Pt}\end{array}$ & $\begin{array}{r}-1.8736 \mathrm{eV} \\
-1.6620 \mathrm{eV} \\
-2.6238 \mathrm{eV} \\
1.0912 \mathrm{eV} \\
1.2400 \mathrm{eV} \\
5.6875 \mathrm{eV} \\
-2.5496 \mathrm{eV} \\
1.3574 \mathrm{eV}\end{array}$ \\
\hline
\end{tabular}
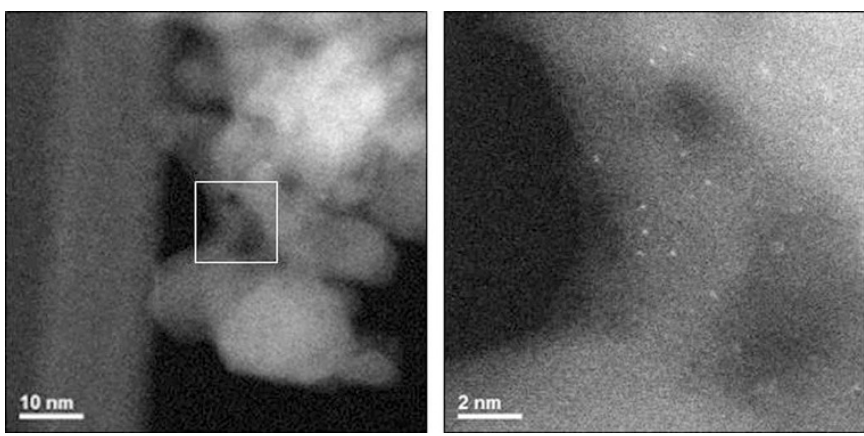

Figure $2 \mid \mathrm{ACEM}$, HAADF-STEM imaging of $0.18 \% \mathrm{Pt} / \boldsymbol{\theta}-\mathrm{Al}_{2} \mathrm{O}_{3}$, after NO oxidation testing up to $415^{\circ} \mathrm{C}$. Low magnification (left) shows alumina and mono-dispersed $\mathrm{Pt}$ atoms can be seen at higher magnification (right). Image on right corresponds to white box area on left

the increase in activity is not related to platinum particle sintering as evinced from atomic imaging of the tested sample by aberrationcorrected electron microscopy (ACEM) of $0.18 \% \mathrm{Pt} / \theta-\mathrm{Al}_{2} \mathrm{O}_{3}$ after testing at all three temperatures, which showed predominantly well dispersed single atoms [Figure 2].

For comparison, we also examined the $\mathrm{NO}$ oxidation activity of $2 \% \mathrm{Pt} / \theta-\mathrm{Al}_{2} \mathrm{O}_{3}$ and $2 \% \mathrm{Pt}_{\mathrm{S}} / \theta-\mathrm{Al}_{2} \mathrm{O}_{3}-650 \mathrm{C}$ keeping the surface $\mathrm{Pt}$ constant to limit $\mathrm{NO}$ oxidation variations to only $\mathrm{Pt}$ morphology variations. The $2 \% \mathrm{Pt} / \theta-\mathrm{Al}_{2} \mathrm{O}_{3}$ catalyst contains $10-20$ atom $\mathrm{Pt}$ rafts composed of Pt atoms that are not close enough for Pt-Pt bonding and are likely connected through $\mathrm{Pt}-\mathrm{O}-\mathrm{Pt}$ bonds ${ }^{19}$. The $2 \% \mathrm{Pt}_{\mathrm{S}} / \theta-$ $\mathrm{Al}_{2} \mathrm{O}_{3}-650 \mathrm{C}$, on the other hand, contains primarily large particles ${ }^{19}$. The NO oxidation over $2 \% \mathrm{Pt} / \theta-\mathrm{Al}_{2} \mathrm{O}_{3}$ at 265,325 , and $415^{\circ} \mathrm{C}$ is ca. 5 , 10.5 , and $17.5 \%$, respectively and that over $2 \% \mathrm{Pt}_{\mathrm{S}} / \theta-\mathrm{Al}_{2} \mathrm{O}_{3}-650 \mathrm{C}$ at 265,325 , and $415^{\circ} \mathrm{C}$ is ca. 7,12 , and $16 \%$, respectively. These data show that the $\mathrm{NO}$ oxidation catalyzed by $2 \% \mathrm{Pt} / \theta-\mathrm{Al}_{2} \mathrm{O}_{3}$ is comparable to that catalyzed by $0.18 \% \mathrm{Pt} / \theta-\mathrm{Al}_{2} \mathrm{O}_{3}$ at $265^{\circ} \mathrm{C}$ but becomes more comparable to $2 \% \mathrm{Pt}_{\mathrm{S}} / \theta-\mathrm{Al}_{2} \mathrm{O}_{3}-650 \mathrm{C}$ at 325 and $415^{\circ} \mathrm{C}$, probably due to sintering. Sintering of $\mathrm{Pt}$ rafts to particles under NO oxidation condition has been previously reported ${ }^{28}$. The atomic imaging of the $2 \% \mathrm{Pt} / \theta-\mathrm{Al}_{2} \mathrm{O}_{3}$ sample after testing confirms that some of the Pt rafts undergo sintering to $\sim 5 \mathrm{~nm}$ particles although many rafts and some single atoms still remain in the sample [Figure S6]. For completeness, we also carried out $\mathrm{NO}$ oxidation over $2 \% \mathrm{Pt}_{\mathrm{T}} / \theta$ $\mathrm{Al}_{2} \mathrm{O}_{3}-650 \mathrm{C}$ where total Pt content is identical to that of $0.18 \% \mathrm{Pt} / \theta$ $\mathrm{Al}_{2} \mathrm{O}_{3}$. The $\mathrm{NO}$ oxidation over $2 \% \mathrm{Pt}_{\mathrm{T}} / \theta-\mathrm{Al}_{2} \mathrm{O}_{3}-650 \mathrm{C}$ at 265,325 , and $415^{\circ} \mathrm{C}$ is 3,7 , and $11 \%$, respectively.

The turn-over-frequencies (TOFs) at steady state for all catalysts are presented in Table 2. The TOFs were calculated using platinum distribution data ${ }^{19}$ from fresh samples. This approach works well for samples of $0.18 \% \mathrm{Pt} / \theta-\mathrm{Al}_{2} \mathrm{O}_{3}$ and $2 \% \mathrm{Pt}_{\mathrm{S}} / \theta-\mathrm{Al}_{2} \mathrm{O}_{3}-650 \mathrm{C}$ since they do not change during $\mathrm{NO}$ oxidation. The TOF data for $2 \% \mathrm{Pt} / \theta-\mathrm{Al}_{2} \mathrm{O}_{3}$ at $315^{\circ} \mathrm{C}$ and $415^{\circ} \mathrm{C}$ are estimates since some of the $\mathrm{Pt}$ in the sample undergoes sintering resulting in a reduced Pt dispersion. An interesting conclusion from TOF data is that the TOF of the single atoms in $0.18 \% \mathrm{Pt} / \theta-\mathrm{Al}_{2} \mathrm{O}_{3}$ and the large particles in $2 \% \mathrm{Pt}_{\mathrm{S}} / \theta-\mathrm{Al}_{2} \mathrm{O}_{3}-650 \mathrm{C}$ are comparable under the test conditions for NO oxidation at $415^{\circ} \mathrm{C}$.

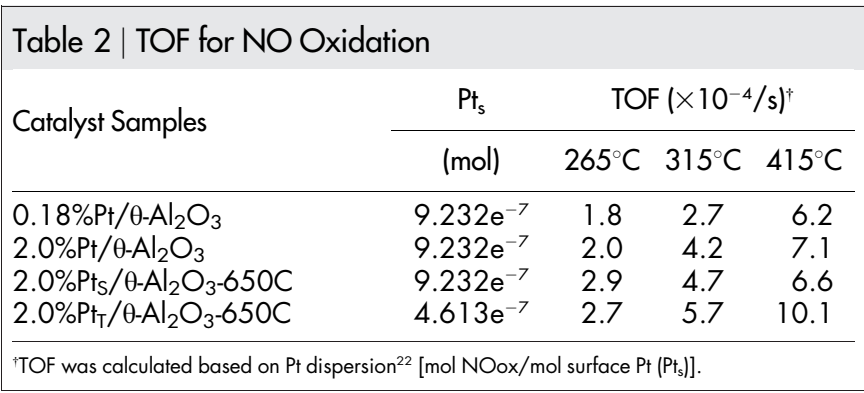




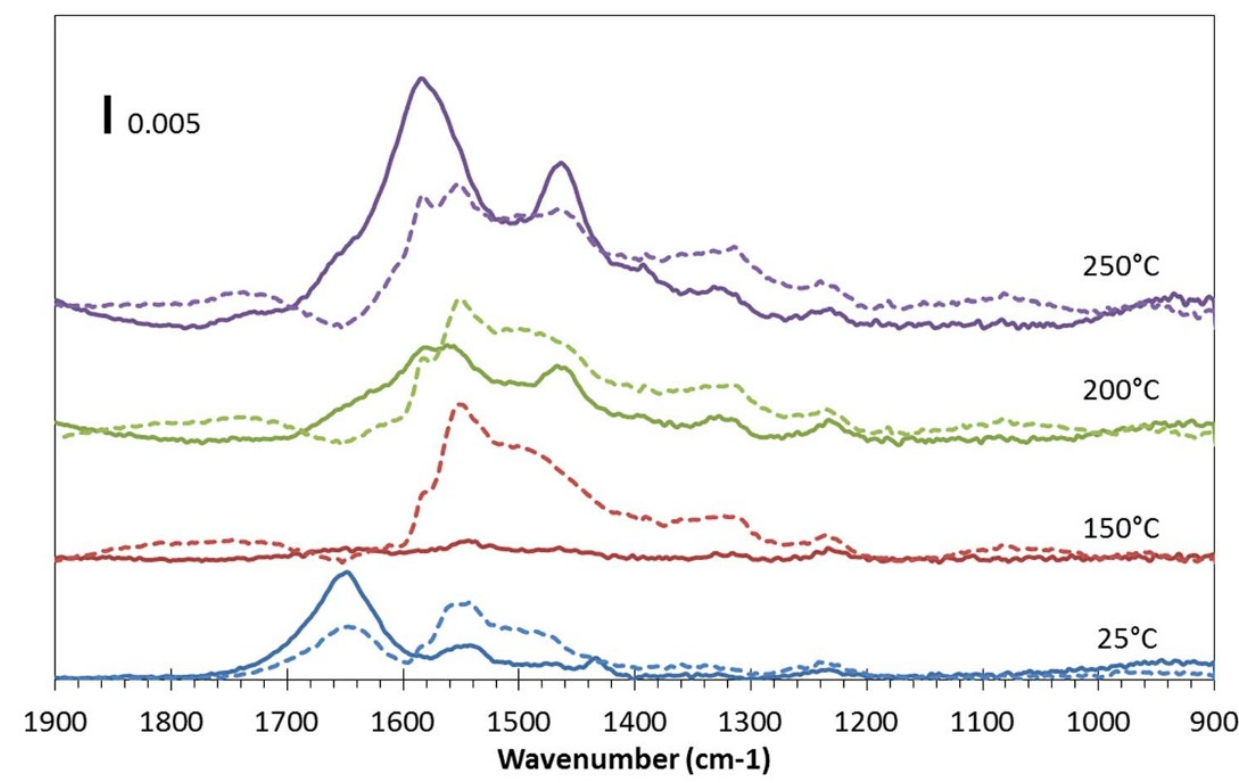

Figure $3 \mid$ DRIFTS of NO adsorption on alumina (dotted lines) and $0.18 \% \mathrm{Pt} / \mathbf{\theta}-\mathrm{Al}_{2} \mathrm{O}_{3}$ (solid lines) in $25-250^{\circ} \mathrm{C}$ range under $\mathrm{NO}$.

Previous work in literature has shown that NO oxidation decreases with decrease in Pt particle ${ }^{29,30}$. The extrapolation of literature data suggests that TOF at single atoms would approach zero for NO oxidation. The high TOF on single supported Pt atoms could be due to a different pathway for NO oxidation.

The TOF of $2 \% \mathrm{Pt} / \theta-\mathrm{Al}_{2} \mathrm{O}_{3}$ at $265^{\circ} \mathrm{C}$ is comparable to that of $0.18 \% \mathrm{Pt} / \theta-\mathrm{Al}_{2} \mathrm{O}_{3}$ but becomes more comparable to $2 \% \mathrm{Pt} / \theta-\mathrm{Al}_{2} \mathrm{O}_{3}$ $650 \mathrm{C}$ at $315^{\circ} \mathrm{C}$ and $415^{\circ} \mathrm{C}$ due to Pt sintering. At $415^{\circ} \mathrm{C}$, NO conversion of all three samples showed similar conversion and TOFs. The TOF of $2 \% \mathrm{Pt}_{\mathrm{S}} / \theta-\mathrm{Al}_{2} \mathrm{O}_{3}-650 \mathrm{C}$ and $2 \% \mathrm{Pt}_{\mathrm{T}} / \theta-\mathrm{Al}_{2} \mathrm{O}_{3}-650 \mathrm{C}$ were similar at $265^{\circ} \mathrm{C}$ when normalized for available surface Pt. However, by $315^{\circ} \mathrm{C}$, the reduced number of available active sites in $2 \% \mathrm{Pt}_{\mathrm{T}} / \theta-\mathrm{Al}_{2} \mathrm{O}_{3}-650 \mathrm{C}$ showed a slight improvement in intrinsic activity compared with $2 \% \mathrm{Pt}_{\mathrm{S}} / \theta-\mathrm{Al}_{2} \mathrm{O}_{3}-650 \mathrm{C}$ which became more pronounced by $415^{\circ} \mathrm{C}$ (Table 2). This increase may be related to increased $\mathrm{NO}_{2}$ inhibition on $\mathrm{NO}$ oxidation? .

These results validate the proposal from theoretical modeling that single supported $\mathrm{Pt}$ atoms can catalyze NO oxidation.

Diffuse Reflectance Infra-Red Spectroscopy of NO adsorption on $\mathbf{0 . 1 8} \% \mathrm{Pt} / \mathbf{\theta}-\mathbf{A l}_{2} \mathrm{O}_{3}$. The role of the alumina support has been examined previously during $\mathrm{NO}$ oxidation and it has been found to be inactive toward NO oxidation ${ }^{29}$. An in-situ FTIR study has shown that $\mathrm{NO}$ or $\mathrm{NO}_{2}$ adsorbs on alumina weakly at $250^{\circ} \mathrm{C}$ to form nitrates that desorb under a helium flush ${ }^{16}$. In the absence of oxygen, platinum supported on alumina also weakly adsorbs NO or $\mathrm{NO}_{2}$ to form products that are identical to alumina except an additional nitrosium species (-NO-) is also observed ${ }^{31}$. The presence of oxygen in the reactant stream, on the other hand, dramatically increases $\mathrm{NO}_{2}$ formation while the nitrosium species disappears ${ }^{31}$. Considering that $\mathrm{NO}$ oxidation over single supported $\mathrm{Pt}$ atoms cannot occur via conventional $\mathrm{L}-\mathrm{H}$ scheme, we carried out diffuse reflectance Fourier transform spectroscopic study (DRIFTS) of $\mathrm{NO}$ adsorption in the absence and presence of oxygen over $\theta$ $\mathrm{Al}_{2} \mathrm{O}_{3}$ and $0.18 \% \mathrm{Pt} / \theta-\mathrm{Al}_{2} \mathrm{O}_{3}$.

The $\theta$-alumina sample, at room temperature shows monodentate nitrate (asymmetric $\mathrm{NO}_{2}$ stretch at $1550 \mathrm{~cm}^{-1}$ and symmetric $\mathrm{NO}_{2}$ stretch at $1257 \mathrm{~cm}^{-1}$ ) and linear nitrite as a shoulder at $1460 \mathrm{~cm}^{-1}$ [Figure 3] ${ }^{32}$. There is also a peak at $1650 \mathrm{~cm}^{-1}$ due to residual bicarbonate which disappears upon increasing the temperature to $150^{\circ} \mathrm{C}$ and chelating nitrate $\left(\mathrm{N}=\mathrm{O}\right.$ stretch at $1590 \mathrm{~cm}^{-1}$ and asymmetric $\mathrm{NO}_{2}$ stretch at $1305 \mathrm{~cm}^{-1}$ ) appears ${ }^{32}$. In addition, a broad peak in
$1650-1900 \mathrm{~cm}^{-1}$ is also observed which could have components of linear NO and residual gaseous NO. Increasing the temperature to 200 or $250^{\circ} \mathrm{C}$ does not significantly change the spectrum except nitrate and nitrite stretches become better defined. Exposure to $\mathrm{NO}$ and $\mathrm{O}_{2}$ [Figure 4] at $250^{\circ} \mathrm{C}$ results in an increase in bands for chelating nitrate at $1590 \mathrm{~cm}^{-1}$ and monodentate nitrate at $1550 \mathrm{~cm}^{-1}$ is not separate. In addition, the broad band in $1650-$ $1900 \mathrm{~cm}^{-1}$ narrows and is centered at $1732 \mathrm{~cm}^{-1}$ probably due to adsorbed linear NO. Increasing the temperature to $300^{\circ} \mathrm{C}$ leads to separation of bands for chelating and monodentate nitrate.

The spectrum of $\mathrm{NO}$ adsorbed on $0.18 \% \mathrm{Pt} / \theta-\mathrm{Al}_{2} \mathrm{O}_{3}$ does not show a peak at $1727 \mathrm{~cm}^{-1}$ previously assigned to $\mathrm{NO}$ linearly bound to $\mathrm{Pt}$ at any temperature [Figure 3] ${ }^{33}$. The residual bicarbonate peak at $1650 \mathrm{~cm}^{-1}$ seen for NO adsorption on $\theta$-alumina was also observed on $0.18 \% \mathrm{Pt} / \theta-\mathrm{Al}_{2} \mathrm{O}_{3}$ at $25^{\circ} \mathrm{C}$ and disappears on increasing the temperature. The peaks due to monodentate nitrate can be seen at $1550 \mathrm{~cm}^{-132}$. There is a unique band at $1432 \mathrm{~cm}^{-1}$ which can be assigned to non-coordinated carbonates. This band also disappears on increasing the temperature. At $200^{\circ} \mathrm{C}$, the peaks due to monodentate and chelating nitrate are seen at 1550 and $1580 \mathrm{~cm}^{-1}$ and the peaks due to linear and bridging nitrite are seen at 1460 and $1314 \mathrm{~cm}^{-1}$. Interestingly, the bent Pt-NO peak, reported in the literature to be present at $1630 \mathrm{~cm}^{-1}$ can be seen as a shoulder ${ }^{33}$. Increasing temperature to $250^{\circ} \mathrm{C}$ results in an increase in intensity of chelating nitrate peak at $1580 \mathrm{~cm}^{-1}$. As a result, the monodentate nitrate peak and bent Pt-NO peak can be seen only as shoulders. A weak peak at $\sim 1390 \mathrm{~cm}^{-1}$, assignable to free nitrate, can also be observed. Exposure to $\mathrm{NO}+\mathrm{O}_{2}$ mixture [Figure 4] at $250^{\circ} \mathrm{C}$ results in monodentate and chelate nitrate peaks at 1550 and $1583 \mathrm{~cm}^{-1}$, respectively, to be almost equal in intensity. In addition, the NO linear peak can be seen at $1735 \mathrm{~cm}^{-1}$. Since Pt-free alumina shows this peak for both $\mathrm{NO}$ and $\mathrm{NO}+\mathrm{O}_{2}$ while $0.18 \% \mathrm{Pt} / \theta-\mathrm{Al}_{2} \mathrm{O}_{3}$ exhibits it only for $\mathrm{NO}+\mathrm{O}_{2}$ gas mixture, we assign this peak to have a contribution of Pt-NO also.

Thus, the DRIFTS data clearly show that the primary differences between NO adsorption on supported Pt particles and single atoms is that the single atoms bond with NO only in bent mode in the absence of oxygen. The single supported Pt atoms are highly active towards NO oxidation since nitrate and nitrite peaks on Pt-containing alumina are much stronger than Pt-free alumina even in the absence of oxygen. This phenomenon has also been previously observed for alumina-supported Pt particles ${ }^{32}$. 


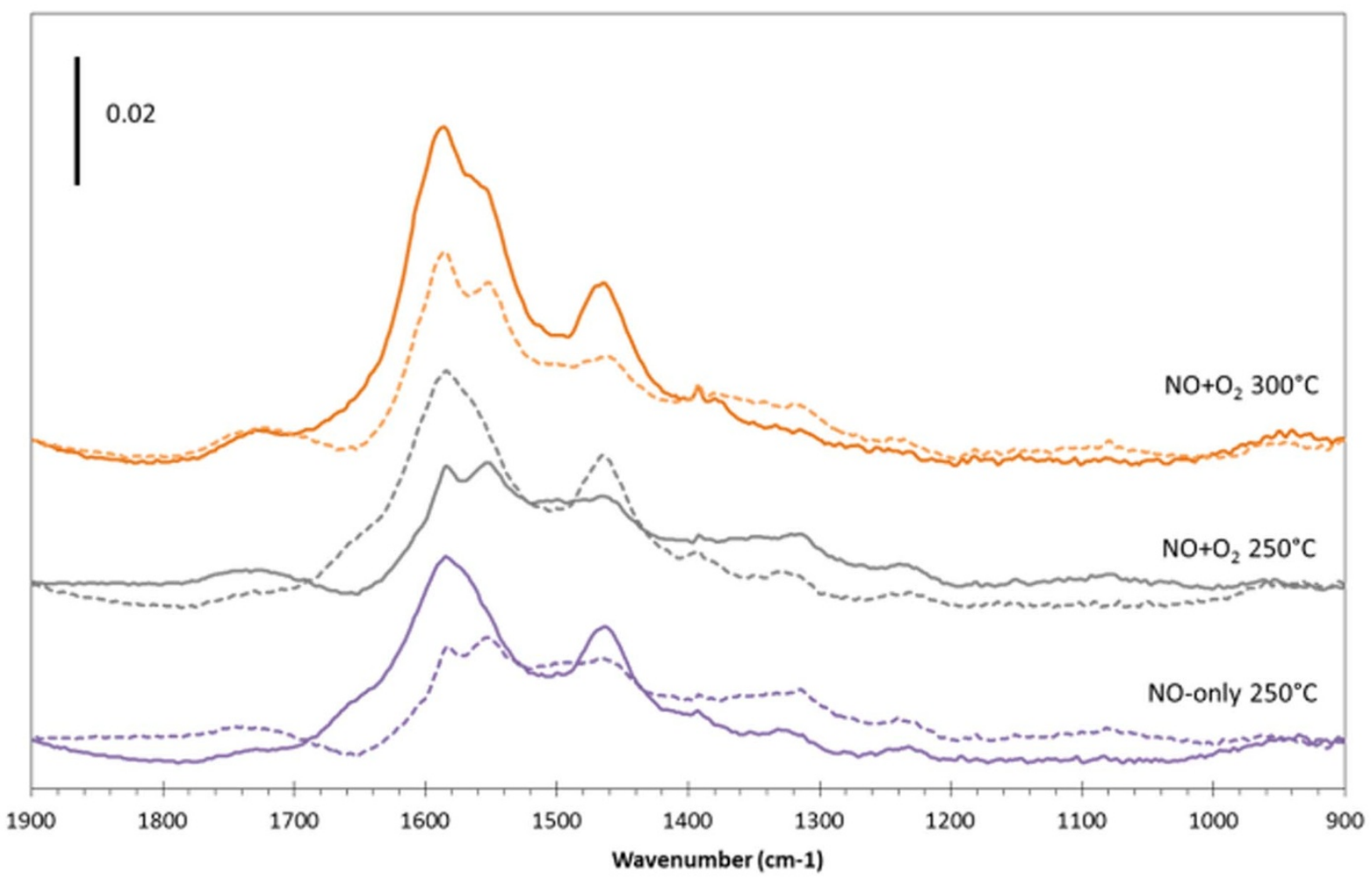

Figure $4 \mid$ DRIFTS of NO adsorption on alumina (dotted lines) and $0.18 \% \mathrm{Pt} / \theta-\mathrm{Al}_{2} \mathrm{O}_{3}$ (solid lines) in $250-300^{\circ} \mathrm{C}$ range under $\mathrm{NO}+\mathrm{O}_{2}$.

The DRIFTS data are consistent with the proposed mechanism but the strong adsorptions of all species on alumina interfere with obtaining species bonded to Pt only. The absence of linear NO in $0.18 \% \mathrm{Pt} / \theta-\mathrm{Al}_{2} \mathrm{O}_{3}$ when exposed to $\mathrm{NO}$ only is an indication that configuration II is not seen due to its transformation to nitrate. Since monodentate and chelating nitrate, bent NO, linear and bridging nitrite are also present in alumina, we refrain from using these observation in support of the proposed mechanism.

\section{Conclusions}

In conclusion, the results of first-principles theoretical modeling enable us to propose that NO oxidation on single supported platinum atoms is feasible although it is quite well known that NO oxidation decreases with decrease in particles size of supported $\mathrm{Pt}$ catalysts. The proposed pathway for NO oxidation is a modified L-H mechanism that does not involve the support and does not require dissociative oxygen adsorption. Experimental validation of our proposal comes from measuring the NO oxidation activity of single supported platinum atoms on an alumina catalyst, $0.18 \% \mathrm{Pt} / \theta$ $\mathrm{Al}_{2} \mathrm{O}_{3}$. Imaging of the single-atom catalyst, $0.18 \% \mathrm{Pt} / \theta-\mathrm{Al}_{2} \mathrm{O}_{3}$, after steady state testing from $265-415^{\circ} \mathrm{C}$, shows that this supported $\mathrm{Pt}$ catalyst remains predominately single atoms.

The $\mathrm{NO}$ oxidation on $2 \% \mathrm{Pt} / \theta-\mathrm{Al}_{2} \mathrm{O}_{3}$, containing $10-20$ atom rafts, is similar to the supported single-atom catalyst but rapidly changes to mimic the large particle catalyst, $2 \% \mathrm{Pt} / \theta-\mathrm{Al}_{2} \mathrm{O}_{3}-650 \mathrm{C}$, due to partial sintering of rafts. The lower TOF observed for $2 \% \mathrm{Pt} / \theta-\mathrm{Al}_{2} \mathrm{O}_{3}$ compared to the pre-sintered $\mathrm{Pt}$ particles in $2 \% \mathrm{Pt} / \theta-\mathrm{Al}_{2} \mathrm{O}_{3}-650 \mathrm{C}$ at $315^{\circ} \mathrm{C}$ supports the well-known size dependent effect of the $\mathrm{L}-\mathrm{H}$ mechanism.

\section{Methods}

Catalyst Preparation. The $\theta-\mathrm{Al}_{2} \mathrm{O}_{3}$ support was prepared by a sol-gel process ${ }^{34,35}$ and platinum samples $\left[0.18 \% \mathrm{Pt} / \theta-\mathrm{Al}_{2} \mathrm{O}_{3}, 2.0 \% \mathrm{Pt} / \theta-\mathrm{Al}_{2} \mathrm{O}_{3}\right.$, and $\left.2.0 \% \mathrm{Pt} / \theta-\mathrm{Al}_{2} \mathrm{O}_{3}-650 \mathrm{C}\right]$ were prepared by wet impregnation as reported previously ${ }^{19}$. All other materials were commercially available and used without further purification.

The $0.18 \% \mathrm{Pt} / \theta-\mathrm{Al}_{2} \mathrm{O}_{3}$ catalyst consists of only single $\mathrm{Pt}$ atoms well dispersed on the alumina support ${ }^{19}$. The $2.0 \% \mathrm{Pt} / \theta-\mathrm{Al}_{2} \mathrm{O}_{3}$ catalyst is composed of both single $\mathrm{Pt}$ atoms and 10-20 atom agglomerates, also referred to as platinum rafts bonded through oxygen $(\mathrm{Pt}-\mathrm{O}-\mathrm{Pt})^{19}$. The $2.0 \% \mathrm{Pt} / \theta-\mathrm{Al}_{2} \mathrm{O}_{3}-650 \mathrm{C}$ catalyst sample is a pre-sintered version of the $2.0 \% \mathrm{Pt} / \theta-\mathrm{Al}_{2} \mathrm{O}_{3}$ raft sample that was thermally treated at $650^{\circ} \mathrm{C}$ to produce a catalyst with predominately well-defined Pt particles ${ }^{19}$.

Aberration-corrected high-resolution electron micrographs of catalyst samples were recorded on a JEOL 2200FS FEG $200 \mathrm{kv}$ (scanning) transmission electron microscope (STEM), equipped with a CEOS GmbH (Heidelberg, Ger.) hexapole corrector on the probe-forming lenses. High-angle annular dark-field (HA-ADF) images showing single $\mathrm{Pt}$ atoms at a nominal resolution of $0.07 \mathrm{~nm}$ were collected at a $26.5 \mathrm{mr}$ incidence semi-angle, using a detector having a $110 \mathrm{mr}$ inner semi-angle.

In situ diffuse reflectance FT infrared spectroscopy (DRIFTS) measurement was performed on a Nicolet Nexus 670 spectrometer equipped with a MCT detector cooled by liquid nitrogen, and an in situ chamber (HC-900, Pike Technologies) with capability to heat samples to $900^{\circ} \mathrm{C}$. The exiting stream was analyzed by an online quadrupole mass spectrometer (QMS) (OmniStar GSD-301 O2, Pfeffer Vacuum). All samples studied by DRIFTS were first heated to $150^{\circ} \mathrm{C}$ under a flow of $100 \mathrm{sccm}$ of $4 \% \mathrm{H}_{2}$ in helium at a rate of $3{ }^{\circ} \mathrm{C} / \mathrm{min}$ and held at that temperature for $45 \mathrm{mins}$. The $\theta$ $\mathrm{Al}_{2} \mathrm{O}_{3}$ sample was then cooled to $25^{\circ} \mathrm{C}$ under a flow of $100 \mathrm{sccm}$ of helium. All spectra were obtained after exposure to $500 \mathrm{ppm}$ NO in helium for 5 minutes. The sample was flushed with helium prior to temperature ramps under flowing helium. The $25^{\circ} \mathrm{C}$ spectrum of $0.18 \% \mathrm{Pt} / \theta-\mathrm{Al}_{2} \mathrm{O}_{3}$ was obtained similar to the $\theta-\mathrm{Al}_{2} \mathrm{O}_{3}$ sample. A second $0.18 \% \mathrm{Pt} / \theta-\mathrm{Al}_{2} \mathrm{O}_{3}$ sample was reduced as described above without cooling. Instead the sample was flushed with helium at $150^{\circ} \mathrm{C}$ before exposure to the $500 \mathrm{ppm}$ NO gas. The rest of the spectra were obtained from this second sample similar to the procedure previously described for $\theta-\mathrm{Al}_{2} \mathrm{O}_{3}$. The oxidizing environment contained $500 \mathrm{ppm} \mathrm{NO}$ and $4.75 \% \mathrm{O}_{2}$. No helium flush was done at $250^{\circ} \mathrm{C}$ before exposure to the oxidizing flow or when ramping from 250 to $300^{\circ} \mathrm{C}$. Space velocity conditions were kept constant from sample to sample. Each DRIFT spectrum was taken from a series recorded at a frequency of 16 scans per minute. The spectra presented in Figures 3 and 4 all had an automatic baseline correction applied for the reported 900$1900 \mathrm{~cm}^{-1}$ region.

NO Catalytic Activity Measurements. NO oxidation reactions were performed in a plug flow reactor and analyzed by a California Analytical, Inc. 400 HCLD NO analyzer. Powder catalyst samples were loaded in a U-tube quartz reactor between two quartz wool plugs. The catalyst temperature was monitored by a type $K$ thermocouple positioned in the catalyst bed. The U-tube was heated in a reactor furnace controlled by another type $K$ thermocouple located at the same height as the catalyst sample. In order to keep a constant gas hourly space velocity (GHSV) of $\sim 55.5 \mathrm{k} \mathrm{h}^{-1}$, the platinum catalysts were mixed with blank $\theta-\mathrm{Al}_{2} \mathrm{O}_{3}$ to provide $120 \mathrm{mg}$ test samples $(0.108 \mathrm{~mL})$ for all tests. The feed gas composition was $50 \mathrm{ppm}$ $\mathrm{NO}, 1 \% \mathrm{O}_{2}$ and $\mathrm{Ar}$ as a balance. In order to achieve the low flow rate of $\mathrm{O}_{2}$, a tank of zero air was used, introducing $3.76 \% \mathrm{~N}_{2}$ into the total flow composition which was maintained at $100 \mathrm{sccm}$. The catalysts were heated to $120^{\circ} \mathrm{C}$ under argon before the 
$\mathrm{NO}+\mathrm{O}_{2}$ reaction gas was introduced and the sample was further heated to the evaluation temperatures. Each sample was studied sequentially at the following set points: $270^{\circ} \mathrm{C}, 320^{\circ} \mathrm{C}$ and $420^{\circ} \mathrm{C}$. The furnace was ramped at $4{ }^{\circ} \mathrm{C} / \mathrm{min}$ to $20^{\circ} \mathrm{C}$ below the set point and held for $5 \mathrm{~min}$ before ramping at $1{ }^{\circ} \mathrm{C} / \mathrm{min}$ for the final $20^{\circ} \mathrm{C}$. The catalyst was held at the set point and allowed to stabilize for $\sim 70 \mathrm{~min}$ before the $\mathrm{NO}_{\mathrm{x}}$ concentration was averaged over $5 \mathrm{~min}$. The analyzer was switched to NO mode and given 1-2 minutes to stabilize, and then the NO concentration was averaged over the next $5 \mathrm{~min}$. The $\mathrm{NO}$ oxidation activity was calculated as $\left(\mathrm{NO}_{\mathrm{x}}-\mathrm{NO}\right) / \mathrm{NO}_{\mathrm{x}}$. Catalyst comparisons were made keeping either the total platinum or surface platinum constant. TOF was calculated as moles of $\mathrm{NO}$ oxidized per mole of surface platinum $\left(\mathrm{Pt}_{\mathrm{s}}\right)$ present in the fresh samples.

Computational Methods. The total energy calculations, based on ab initio density functional theory, were carried out employing the Vienna Ab Initio Simulation Package (VASP) ${ }^{36}$. A generalized gradient approximation (GGA) in the PerdewWang-91 form was employed for the electron exchange and correlation potential ${ }^{37,38}$. The projector-augmented wave (PAW) approach for describing electronic core states was employed to solve Kohn-Sham equation ${ }^{39,40}$. The plane wave basis set was truncated at a kinetic energy cutoff of $500 \mathrm{eV}$. As described previously, a Gaussian smearing function with a width of $0.05 \mathrm{eV}$ was applied near Fermi levels. Ionic relaxations were considered converged when the forces on the ions were $0.03 \mathrm{eV} / \mathrm{A}$.

1. Shelef, M. \& McCabe, R. W. Twenty five years after introduction of automotive catalysts: what next? Catal. Today 62, 35-50 (2000).

2. Gandhi, H. S., Graham, G. W. \& McCabe, R. W. Automotive exhaust catalysis J. Catal. 216, 433-442 (2003).

3. Jobson, E. Future challenges in automotive emission control. Top. Catal. 28, 191-199 (2004).

4. Olsson, L. et al. A kinetic study of oxygen adsorption/desorption and NO oxidation over $\mathrm{Pt} / \mathrm{Al}_{2} \mathrm{O}_{3}$ catalysts. J. Phys. Chem. B 103, 10433-10439 (1999).

5. Olsson, L., Persson, H., Fridell, E., Skoglundh, M. \& Andersson, B. A kinetic study of $\mathrm{NO}$ oxidation and $\mathrm{NO}_{\mathrm{x}}$ storage on $\mathrm{Pt} / \mathrm{Al}_{2} \mathrm{O}_{3}$ and $\mathrm{Pt} / \mathrm{BaO} / \mathrm{Al}_{2} \mathrm{O}_{3}$. J. Phys. Chem. B 105, 6895-6906 (2001)

6. Bartram, M. E., Windham, R. G. \& Koel, B. E. The molecular adsorption of nitrogen dioxide on $\mathrm{Pt}(111)$ studied by temperature programmed desorption and vibrational spectroscopy. Surf. Sci. 184, 57-74 (1987).

7. Bartram, M. E., Windham, R. G. \& Koel, B. E. Coadsorption of nitrogen-dioxide and oxygen on $\mathrm{Pt}(111)$. Langmuir 4, 240-246 (1988).

8. Parker, D. H., Bartram, M. E. \& Koel, B. E. Study of high coverages of atomic oxygen on the Pt(111) surface. Surf. Sci. 217, 489-510 (1989).

9. Mulla, S., Chen, N., Deglass, W. N., Epling, W. S. \& Ribeiro, F. H. NO 2 inhibits the catalytic reaction of $\mathrm{NO}$ and $\mathrm{O}_{2}$ over Pt. Catal. Lett. 100, 267-270 (2005).

10. Mulla, S. et al. Effect of potassium and water vapor on the catalytic reaction of nitric oxide and dioxygen over platinum. Catal. Today 114, 114, 57-63 (2006).

11. Mulla, S. et al. Reaction of $\mathrm{NO}$ and $\mathrm{O}_{2}$ to $\mathrm{NO}_{2}$ on Pt: Kinetics and catalyst deactivation. J. Catal. 241, 389-399 (2006).

12. Smeltz, A. D., Getman, R. B., Schneider, W. F. \& Ribeiro, F. H. Coupled theoretical and experimental analysis of surface coverage effects in Pt-catalyzed $\mathrm{NO}$ and $\mathrm{O}_{2}$ reaction to $\mathrm{NO}_{2}$ on $\mathrm{Pt}(111)$. Catal. Today 136, 136, 84-92 (2008).

13. Weiss, B. M. \& Iglesia, E. NO oxidation catalysis on Pt Clusters: Elemntary steps, structural requirements, and synergistic effects of $\mathrm{NO}_{2}$ adsorption sites. J. Phys. Chem. C 113, 13331-13340 (2009).

14. Wang, H.-F., Guo, Y.-L., Lu, G. \& Hu, P. NO oxidation on platinum group metal oxides: First principles calculations combined with microkinetic analysis. J. Phys. Chem. C, 113, 18746-18752 (2009).

15. Fu, Q., Saltsburg, H. \& Flytzani-Stephanopoulos, M. Active nonmetallic Au and Pt species on ceria-based water-gas shift catalysts. Science 301, 935-938 (2003).

16. Hackett, S. E. J. et al. High-activity, single-site, mesoporous $\mathrm{Pd} / \mathrm{Al}_{2} \mathrm{O}_{3}$ catalysts for selective aerobic oxidation of allylic alcohols. Angew. Chem. Int. Ed. 46, 8593-8596 (2007).

17. Qiao, B. T. et al. Single atom catalysis of $\mathrm{CO}$ oxidation using $\mathrm{Pt1} / \mathrm{FeO}_{\mathrm{x}}$. Nat. Chem. 3, 634 (2011).

18. Lin, J. et al. Remarkable performance of $\mathrm{Ir} 1 / \mathrm{FeO}$ single-atom catalyst in water gas shift reaction. J. Am. Chem. Soc., 135, 15314-15317 (2013).

19. Moses-DeBusk et al. CO oxidation on supported single Pt atoms: Experimental and ab initio density functional studies of $\mathrm{CO}$ interaction with $\mathrm{Pt}$ atom on theta$\mathrm{Al}_{2} \mathrm{O}_{3}$ (101) surface. J. Am. Chem. Soc. 135, 12634-12645 (2013).

20. Hu, P. et al. Electronic metal-support interactions in single-atom catalysis. Angew. Chem. Int. Ed. 53, 3418-3421 (2014).

21. Peterson, E. J. et al. Low-temperature carbon monoxide oxidation catalyzed by regenerable atomically dispersed palladium on alumina. Nature Comm. 5, 4885 (2014).

22. Duarte, R. B., Krumeich, F. \& van Bokhoven, J. A. Structure, activity, and stability of atomically dispersed Rh in methane steam reforming. ACS Catal. 4, 1279-1286 (2014)

23. Chemistry Webbook, Standard Reference Database Number 69. 2005.

24. Hong, S., Rahman, T. S., Jacobi, K. \& Ertl, G. Interaction of $\mathrm{NO}_{\text {with }} \mathrm{RuO}_{2}(110)$ surface: A first principles study. J. Phys. Chem. C 111, 12361-123681 (2007).
25. Getman, R. B., Xu, Y. \& Schneider, W. F. Thermodynamics of environmentdependent oxygen chemisorption on Pt(111). J. Phys. Chem. C 112, 9559-9572 (2008).

26. Narula, C. K. \& Stocks, G. M. Ab Initio density functional calculations of adsorption of transition metal atoms on theta- $\mathrm{Al}_{2} \mathrm{O}_{3}(010)$ surface. J. Phys. Chem. C, 116, 5628-5636 (2012).

27. Countryman, R. \& McDonald, W. S. trans-Nitrato[2-(di-tertbutylphosphino)phenyl]- di-tert-butylphenylphosphine-platinum(II). Acta Cryst. B, 33, 33, 3580-3581 (1977).

28. Narula, C. K., Allard, L. F., Blom, D. A. \& Moses-DeBusk, M. Bridging the gap between theory and experiments - nanostructural changes in supported catalyst under operating conditions. SAE Int. J. Mater. Manuf. 1, 182-188 (2009).

29. Xue, E., Seshan, K. \& Ross, J. R. H. Role of support, Pt loading and Pt dispersion in the oxidation of $\mathrm{NO}$ to $\mathrm{NO}_{2}$ and of $\mathrm{SO}_{2}$ to $\mathrm{SO}_{3}$. Appl. Catal. B, 11, 65-79 (1996).

30. Matam, S. K. et al. The impact of aging environment on the evolution of $\mathrm{Al}_{2} \mathrm{O}_{3}$ supported Pt nanoparticles and their NO oxidation activity. Appl. Chem. B 129, 214-224 (2013).

31. Captain, D. K. \& Amiridis, M. D. In situ FTIR studies of the selective catalytic reduction of $\mathrm{NO}$ by $\mathrm{C}_{3} \mathrm{H}_{6}$ over $\mathrm{Pt} / \mathrm{Al}_{2} \mathrm{O}_{3}$. J. Catal. 184, 377-389 (1999).

32. Toops, T. J., Smith, D. B., Epling, W. E., Parks, J. E. \& Partridge, W. P. Quantified $\mathrm{NO}_{\mathrm{x}}$ adsorption on Pt/K/gamma- $\mathrm{Al}_{2} \mathrm{O}_{3}$ and the effects of $\mathrm{CO}_{2}$ and $\mathrm{H}_{2} \mathrm{O}$. Appl. Catal. B, 58, 255-264 (2005).

33. Chilukoti, S. et al. Spectral reconstruction of surface adsorbed species using bandtarget entropy minimization. Application to $\mathrm{CO}$ and $\mathrm{NO}$ reaction over a $\mathrm{Pt} / \gamma$ $\mathrm{Al}_{2} \mathrm{O}_{3}$ catalyst using in situ DRIFT spectroscopy. Phys. Chem. Chem. Phys. 10, 3535-3548 (2008)

34. Narula, C. K., Watkins, W. L. H. \& Shelef, M. Aluminum oxide catalyst supports from alumina sols. U.S. Patent no. 5, 210,062 (1993).

35. Leenars, A. F., Keizer, K. \& Burggraaf, A. The preparation and characterization of alumina membranes with ultra-fine pores. J. Mater. Sci. 19, 1077-1088 (1984).

36. Kresse, G. Furthmuller, Efficiency of ab-initio total energy calculations for metals and semiconductors using a plane-wave basis set. J. Comput. Mater. Sci. 6, 15-50 (1996).

37. Kresse, G. \& Joubert, D. From ultrasoft pseudopotentials to the projector augmented-wave method. Phys. Rev. B 59, 1758-1775 (1999).

38. Blochl, P E. Projector augmented-wave method. Phys. Rev. B 50, 17953-17979 (1994).

39. Perdew, J. P. \& Wang, Y. Accurate and simple analytic representation of the electron-gas correlation energy. Phys. Rev. B 45, 13244-13249 (1992).

40. Perdew, J. P. et al. Molecules, solids, and surfaces: Applications of the generalized gradient approximation for exchange and correlation. Phys. Rev. B 46, 6671-6687 (1992).

\section{Acknowledgments}

The research was sponsored by the U.S. Department of Energy, Office of Energy Efficiency and Renewable Energy, Vehicle Technologies Office, Propulsion Materials Program (C.K.N., M.M.D. L.F.A.) and Division of Materials Sciences and Engineering, Office of Basic Energy Sciences (G.M.S.) under contract DE-AC05-ooOR22725 with UT-Battelle, LLC. The DRIFTS studies were conducted at the Center for Nanophase Materials Sciences, which is sponsored at Oak Ridge National Laboratory by the Scientific User Facilities Division, Office of Basic Energy Sciences, U.S. Department of Energy.

\section{Author contributions}

C.N. developed the concept, carried out DFT calculations in collaboration with G.S., and wrote most of the paper. M.D. designed and carried out catalyst preparation, characterization, NO oxidation study including DRIFTS work, and wrote the experimental part in results and methods sections. L.A. conducted STEM examination of samples. All authors discussed the results, and commented on and edited the manuscript.

\section{Additional information}

Supplementary information accompanies this paper at http://www.nature.com/ scientificreports

Competing financial interests: The authors declare no competing financial interests. How to cite this article: Narula, C.K., Allard, L.F., Stocks, G.M. \& Moses-DeBusk, M. Remarkable NO oxidation on single supported platinum atoms. Sci. Rep. 4, 7238; DOI:10.1038/srep07238 (2014)

This work is licensed under a Creative Commons Attribution-NonCommercialShareAlike 4.0 International License. The images or other third party material in this article are included in the article's Creative Commons license, unless indicated otherwise in the credit line; if the material is not included under the Creative Commons license, users will need to obtain permission from the license holder in order to reproduce the material. To view a copy of this license, visit http:// creativecommons.org/licenses/by-nc-sa/4.0/ 